\title{
ELS PRONOMS FORTS EN LES ORACIONS EXISTENCIALS DEL CATALÀ*
}

\author{
STRONG PRONOUNS IN CATALAN \\ EXISTENTIAL SENTENCES
}

\author{
Xavier Villalba \\ Universitat Autònoma de Barcelona \\ xavier.villalba@uab.cat
}

Resum: En aquest article defenso que la distribució restringida dels pronoms forts en les oracions existencials del català és la conseqüència, no pas de l'Efecte de Definitud, com s'ha assumit de manera habitual, sinó de la combinació de les condicions informatives que imposa l'oració existencial, que requereix que el pivot sigui contrastiu, amb la naturalesa pragmàtica del contrast en les formes pronominals, que impedeix la lectura contrastiva justament en aquesta posició. Es proposa, doncs, que els casos de pivot pronominal necessiten obtenir aquesta lectura contrastiva per mitjans alternatius, especialment mitjançant l'aportació de les partícules només i mateix. Aquesta anàlisi es pot estendre a llengües que respecten l'Efecte de Definitud, com ara l'anglès o el castellà.

Paraules clau: pronoms forts, oracions existencials, contrast, focus, estructura informativa.

Abstract: This article defends that the restricted distribution of strong pronouns in the pivot position of Catalan existential sentences is not a consequence of the Definiteness Effect, as commonly assumed, but rather of the conjunction of the information conditions imposed by the existential

(*) Vull agrair els profitosos comentaris dels dos revisors de Caplletra, que han servit per millorar la versió final d'aquest article. També vull agrair els comentaris de les audiències de la Universitat Pompeu Fabra, de la Radboud Universiteit Nijmegen, de la Université de Paris-Diderot i de la Universität Konstanz, on vaig tenir l'oportunitat de presentar part d'aquesta recerca. Finalment, vull fer constar que la recerca en què es basa aquest article ha estat possible gràcies al finançament dels projectes FFI20I4-520I5 i 20I7SGR-634 (Ministerio de Ciencia e Innovación, Spain) i 20I4 SGR-IoI3-P (AGAUR, Generalitat de Catalunya), concedits al Centre de Lingüística Teòrica de la Universitat Autònoma de Barcelona.

Caplletra 65 (Tardor, 2018), pp. 69-94. ISSN 0214-8188, ISSN versió electrònica 2386-7159 Rebut: 05/07/2017. Acceptat: 06/05/2017. DOI: 10.7203/Caplletra.65.12612 
sentence, which requires the pivot to be contrastive, with the pragmatic nature of contrast in the pronominal system, which blocks the contrastive reading of pronouns in precisely this position. Henceforth, it is argued that pronominal pivots can only obtain the required contrastive reading by external means, namely by means of the particles només 'only' and mateix 'same'. This analysis is extended to languages respecting the Definiteness Effect, as English or Spanish.

Key words: strong pronouns, existentials sentences, contrast, focus, information structure.

$\cos \cos$

\section{INTRODUCCIÓ}

Les descripcions gramaticals de les oracions existencials (o presentacionals) del català (Brucart \& Rigau 2002; Ramos I998; Rigau 1988a, 1994a, I994b) destaquen dos fets aparentment contradictoris. D'una banda, el català permet que l'argument nominal del predicat existencial (el pivot), sigui definit i, fins i tot, un nom propi: ${ }^{1}$

(I) a. Hi havia el degà, a la reunió.

b. En aquella assemblea, hi havia la Maria.

Aquest patró és ben sorprenent si el comparem amb el castellà o l'anglès:

(2) a. *Hay el perro/ese perro/Fido. (Leonetti 2008: ex. 2)

b. ${ }^{*}$ There is the $\mathrm{dog} / \mathrm{John}$ in the room. (Milsark 1974: ex. 67)

«Hi ha el gos/en Joan a l'habitació.»

De l'altra, el català comparteix amb totes aquestes llengües la impossibilitat de tenir pronoms personals forts en aquesta posició:

(3) a. *Hi ha ell. (Rigau 1988a: ex. 2d)

b. ${ }^{*}$ En aquella assemblea, hi havia ella, tu i jo. (Ramos i998: ex. 7 b)

(4) a. *Hay él. (Leonetti 2008: ex. 2)

b. ${ }^{*}$ There is him/he in the room. (Milsark 1974: ex. 64)

I. Aquest comportament també és propi de l'italià estàndard, del sard i de molts dialectes italoromànics (Bentley 2014, Bentley et al. 2015 i Cruschina 2015). 
Per norma, l'explicació d'aquest comportament dels pronoms ha estat considerar que es tracta d'un subtipus de l'Efecte de Definitud (ED), que estableix la impossibilitat de tenir elements definits en certes posicions, en el nostre cas en la posició de pivot d'una construcció existencial (veg. els diferents articles en Fischer et al. 20I6, especialment el valuós resum de Leonetti 20I6). Aquesta conclusió sembla afavorida pel fet que en les llengües que respecten l'ED, els sintagmes determinants (SD) definits, els noms propis i els pronoms es poden legitimar en les mateixes condicions, com per exemple en l'anomenada lectura de llista (Abbott 1997; Milsark 1974; Rando \& Napoli 1978):

(5) A. My God! How many people know about this?

B. There's me and there's you. That's all. (Rando \& Napoli i978: ex. 37)

(6) OK, let's finish up this guest list. There's you and me. Who else is coming? (Abbott 1997: 6)

(7) A. I don't have any friends.

B. Oh, don't be silly! There's John and me and Susan and Peggy... (Rando \& Napoli 1978: nota 9)

Aquests casos són típicament respostes que introdueixen elements d'una llista de possibles alternatives (Milsark 1974: 208-9).

Sembla, doncs, que l'ED fa la generalització correcta. No obstant això, quan deixem l'anglès i ens movem al català, les coses no són tan senzilles, perquè la distribució dels SD definits i dels noms propis no coincideix amb la dels pronoms, com ja hem pogut apreciar. Si prenem com a principi explicatiu l'ED, un esperaria un comportament unificat dels pivots, com el que tenim en anglès.

\begin{tabular}{|l|c|c|}
\hline & anglès/castellà & català/italià \\
\hline SD definits & no & sí \\
\hline noms propis & no & sí \\
\hline pronoms & no & no \\
\hline
\end{tabular}

Els pronoms, doncs, tenen alguna cosa peculiar que els fa especialment inapropiats com a pivots de les construccions existencials.

No obstant això, aquesta restricció no és en cap cas absoluta, com ja hem vist per a l'anglès: en certes circumstàncies, la presència d'un pivot pronominal és gramatical. Noteu, per exemple els exemples següents del català, espigolats de la premsa a Internet:

(8) a. Rafael Azcona representa la literatura cinematogràfica. A Itàlia els millors escriptors escrivien per al cinema, però a Espanya, gairebé només hi ha ell. (El Punt, 23/I2/II) 
Xavier Villalba

Els pronoms forts en les oracions existencials del català

b. Keane o Arctic Monkeys tenen bones cançons, però pel que fa a personalitats, només hi ha ella. (El Periódico, 24/07/2012)

Com veurem, aquests exemples plantegen un greu problema a les solucions sintàctiques i semàntiques proposades, perquè no preveuen la possibilitat de «relaxar» la prohibició contra els pivots pronominals en funció del context d'aparició.

Defensaré, doncs, una aproximació pragmàtica al problema, però mostraré que les solucions pragmàtiques proposades tampoc no donen compte del comportament del català (ni de l'italià), per dos motius. D’una banda, assumeixen que l'ED és un fenomen unitari i, per tant, que cal posar els casos dels pivots pronominals en el mateix sac que el dels SD definits i els noms propis. De l'altra, com que s'apliquen a una llengua com l'anglès, no recullen la naturalesa especial dels pronoms forts en les llengües romàniques, la qual cosa els impedeix caracteritzar correctament l'arrel del problema. La meva proposta, en canvi, planteja que el problema dels pivots pronominals no té a veure amb l'ED, sinó amb un conflicte entre els requisits pragmàtics que el predicat existencial imposa al pivot i la naturalesa dels pronoms personals en català.

L'estructura de l'article és la següent. A la secció 2, faig una descripció detallada de la distribució dels pivots pronominals en català. Tot seguit, a la secció 3, repasso breument les diverses formulacions de l'ED: sintàctiques, semàntiques i pragmàtiques, tot mirant de mostrar que l'ED no pot donar compte de manera satisfactòria de la distribució dels pronoms en la posició de pivot de les construccions existencials. Llavors, a la secció 4, presento la meva anàlisi i mostro com dóna compte del paradigma descrit a la secció 2. Finalment, la secció 5 , resumeix les principals conclusions de l'article.

\section{PIVOTS PRONOMINALS EN CATALÀ}

Malgrat les remarques de la bibliografia gramatical, no és estrany trobar pivots pronominals en català, com ens mostra una simple cerca per Internet. ${ }^{2}$ Entre els exemples documentats, podem destacar dos grans grups. En primer lloc, trobem casos en què el pivot s'associa a l'adverbi focal només: ${ }^{3}$

2. No cal dir que aquests exemples no són un estudi de corpus, sinó una mostra d'un fenomen poc estudiat. En un futur, convindria refermar o refutar les conclusions d'aquest treball amb un estudi detallat de corpus que tingués també en compte, com em suggereix un revisor anònim, les diferències entre el català del principat i el valencià. Pel que fa a aquest treball, les dades corresponen majoritàriament al català central.

3. Com apunta un revisor anònim, caldria tenir present la influència que la inestabilitat del sistema dels verbs locatius ser/estar/haver-hi pot tenir en la propagació d'aquest fenomen. Vegeu Ramos (200I, 2002). 
(9) a. Rafael Azcona representa la literatura cinematogràfica. A Itàlia els millors escriptors escrivien per al cinema, però a Espanya, gairebé només hi ha ell. (El Punt, 23/12/II)

b. Si només hi ha ell i la seva obsessió corrosiva, no cal donar més voltes al nan. (Avui, I4 Juny 2010)

c. Keane o Arctic Monkeys tenen bones cançons, però pel que fa a personalitats, només hi ha ella. (El Periódico, 24 de juny)

d. Només hi havia ella i la seva bossa de mà, i prou.

e. Ja no era allà, havia desaparegut... ara, només hi havia ella, la xinesa. Aquest era el cop de puny brutal que l'havia sacsejat: el seu somriure, ...

f. Em va comentar que d'empleats només hi havia ella i una auxiliar, per fer les tasques de venda de bitllets, informació i atenció d'incidències

g. Ningú, només hi havia ella. Tenia la cara envermellida i el somriure torçat

h. Vaig veure, empenat, que en aquella central només hi havia jo. Els altres tenien altres noms i codis

i. O el que jo podria ser si només hi havia jo

j. Doncs aquell dia ell va entrar i només hi havia jo, al pis,

En segon lloc, també trobem exemples amb el reforç mateix:

(io) a. l'endemà es va prendre declaració a les persones relacionades amb l'arxiu, entre les quals hi ha ell mateix, ha explicat el degà. (Diari de Girona, 08/07/20II)

b. Però a partir d'un cert moment, al president li han començat a créixer enemics —entre els quals hi ha ell mateix-. (El Periódico, 09/07/2008)

c. - La seva llista de sospitosos es redueix a un grapat d'homes entre els quals hi ha ell mateix. (El Periódico, 22/06/2012)

d. El quart adhesiu no era gaire més prometedor: «darrere cada dona amb èxit hi ha ella mateixa». (Marie Lorrie Moore, Al peu de l'escala, p. 46)

e. Hinton ha admés a través d'una videoconferència que no és «exacta» la versió esgrimida per alguns responsables del grup empresarial, entre els quals hi ha ell mateix, (Vilaweb, $24 /$ IO/2OII)

Podem dir, doncs, que l'associació amb només i mateix afavoreix l'aparició d'un pivot pronominal: a la secció 4 mirarem de donar una explicació del paper d'aquestes partícules en la legitimació dels pivots pronominals. ${ }^{4}$

4. Aquests dos grups són els més comuns a molta distància dels altres (noteu, per exemple, el cas de també $\mathrm{a}(\mathrm{i}) \mathrm{b}$, del qual només he documentat una ocurrència i el podem considerar, doncs, un hàpax), però no esgoten les possibilitats, com ens ho demostren els exemples següents, que hauran de quedar fora de l'abast d'aquest article:

(i) a. un sopar on hi havia ell i la seua dona, [...] (Ramon Lapiedra, La raó cívica, p. 49) 
Xavier Villalba

Els pronoms forts en les oracions existencials del català

\section{L'EFECTE DE DEFINITUD}

En aquesta secció faig un breu repàs a les diferents formulacions de l'ED en les oracions existencials, tot mirant de mostrar les limitacions que té per donar compte de la restricció sobre els pivots pronominals, independentment de l'orientació adoptada.

\section{I SOLUCIONS SINTÀCTIQUES}

Les solucions sintàctiques que s'han proposat (Belletti 1988; Rigau 1988a; Safir 1985) es basen en la noció de cas abstracte, concretament en l'assignació de cas al pivot. Per a Safir, que estudia l'anglès, els predicats existencials no poden assignar cas al pivot $\mathrm{i}$, per tant, s'ha d'inserir un expletiu (there) que formi una cadena de cas amb el pivot, de manera que l'expletiu rep el cas nominatiu en la posició de subjecte i el transmet al pivot. El problema és que el pivot queda lligat per l'expletiu, cosa que planteja un problema per al principi $\mathrm{C}$ de la Teoria del Lligam, que exigeix que els nominals referencials han de ser sempre lliures. La seva proposta és que aquest requisit és vàlid per als nominals definits, però no pas per als indefinits, que tenen una naturalesa diferent, com ho demostra que puguin funcionar com a predicats:

(II) En Pere és (un) idiota.

Evidentment, aquesta solució és insatisfactòria per al català, però tampoc no pot explicar els casos en què l'anglès admet pivots definits ni, sobretot, els casos amb pronoms, que haurien de ser sempre impossibles, atès que quedarien lligats per l'expletiu en el seu domini i violarien, doncs, el principi B de la Teoria del Lligam.

Belletti (1987, I988), que estudia l'italià, suggereix una línia diferent. Segons aquesta autora, el verb existencial sí que assigna cas al pivot, però no pas cas acusatiu, com faria un verb transitiu, sinó cas partitiu, un cas inherent que va associat a certes restriccions semàntiques, en concret a la inespecificitat $i$, de retruc, a la indefinitud. Esperem, doncs, que el pivot sigui semànticament indefinit i que mai no sigui un pronom. Justament, aquesta és la idea que expressa Rigau (1988a: 5I-52):

b. On hi ha Lancelot també hi ha ella, Ginebra, i l'altre, Artús. Vicent Martines, Els amants i els altres. Una visita al tercer amorós en la literatura medieval, Anuari de l'Associació Borrianenca de Cultura, p. 30 . 


\begin{abstract}
La raó de la agramaticalitat de $(2 \mathrm{~d})\left[={ }^{*} \mathrm{Hi}\right.$ ha ell] pot raure en el fet que els pronoms forts com $j o, t u$, ell, etc., presenten cas inherent nominatiu i els que no són nominatius - $m i$, $t u$, ell, etc.- manifesten cas a través de la presència d'una preposició. No són compatibles, doncs, amb el cas partitiu que els assignaria el verb haver-hi, segons l'anàlisi proposada per Belletti.
\end{abstract}

Aquesta explicació no sembla adequada, si atenem als nombrosos contraexemples del català (vegeu també la secció 4.3 per a casos semblants de l'italià i el castellà):

(I2) a. D'una banda hi havia ella i de l'altra la resta del món,...

b. Ja no era allà, havia desaparegut... ara, només hi havia ella, la xinesa.

c. Manel Serra, va reconèixer que el debat entre els disset consellers, entre els quals $h i$ ha ell mateix, i el director general, Jordi Blanch,

Evidentment, el problema d'una solució sintàctica de l'ED està en l'existència de contextos que permeten violar el principi, com els que hem mostrat a 2, la qual cosa fa que no aporti gaire llum al paper especial dels pronoms com a pivots.

\title{
3.2 SOLUCIONS SEMÀNTIQUES
}

Les solucions semàntiques a l'ED es basen en la naturalesa lògica dels determinants $\mathrm{i}$, concretament, cerquen un fonament independent a la distinció de Milsark (1974, I977) entre determinants forts i determinants febles. Com va descriure Milsark, el pivot d'una existencial ha de tenir un determinant feble (he reduït la llista als principals determinants):

(i3) a. determinants febles: a 'un(a)', one, two, three,... 'un, dos, tres,...'; many 'molts', some 'uns quants', several 'diversos', no 'cap'.

b. determinants forts: every 'cada', the 'el/la', all 'tots els/les', most 'la majoria de', both 'ambdós', neither 'cap dels dos'.

Segons Milsark, els determinants forts són inherentment quantificats i això fa que, quan apareixen en la posició de pivot, es produeixi un conflicte amb el quantificador existencial que introdueix el predicat haver-hi: com que el quantificador existencial ja lliga totes les variables al seu abast, el quantificador introduït pel pivot no pot lligar cap variable i es produeix una quantificació vàcua. En canvi, els determinants febles no són quantificacionals i, per tant, no hi ha cap conflicte. Això explica, segons Milsark, l'ED.

Aquesta anàlisi presenta nombrosos problemes de caire teòric i empíric. Si ens centrem en els primers, resulta molt problemàtic assumir que els SD indefinits no 
són quantificacionals, perquè estableixen relacions d'abast amb altres quantificadors i poden lligar variables. Aquesta conseqüència tan antiintuïtiva se suma a una altra: l'enfocament de Milsark o bé deixa sense explicació la impossibilitat de tenir noms propis a la posició del pivot o bé ha d'assumir que els noms propis són inherentment quantificats.

En el terreny empíric, la solució tampoc no està exempta de problemes. Un cas paradigmàtic és la possibilitat de tenir casos de pivots clarament quantificacionals i amb determinants forts, com els que destaquen Lumsden (1988) i McNally (1992: 35) per a l'anglès:

(I4) a. *There was every doctor. "Hi havia cada doctor.»

b. There was every kind of doctor. «Hi havia tota mena de doctor.»

Si every és impossible a (I4a) perquè és un determinant fort, ens hem de preguntar per què és bona la frase de (I4b).

El quantificador tothom planteja un problema semblant:

(I5) a. Quin poder de convocatòria: hi havia tothom. (Diari de Girona, I8/04/2010)

b. Berga en aquells anys setanta per Corpus era com per la Rambla de Barcelona hi havia tothom que hi tenia de ser. (Regió 7, 8/10/2013)

c. Hi havia tothom. (La Vanguardia, 03/02/2014)

Tot i que no són les formes estàndard, que farien servir ser, aquestes frases no són inhabituals en la premsa escrita; per tant, semblen reflectir un ús en expansió, possiblement afavorit per la inestabilitat en l'ús del sistema de predicats locatius del català (Ramos 200I, 2002).

Finalment, i de manera especialment interessant per al nostre cas, l'explicació de l'ED basada en les propietats dels determinants no s'estén de manera natural al cas dels pronoms forts, que no s'analitzen com a quantificadors generalitzats.

Per tant, tant la proposta de Barwise \& Cooper (198I) com la de Keenan (2003), que formalitzen la distinció feble/fort de Milsark (1974, 1977) en el context de la teoria dels quantificadors generalitzats i miren de derivar l'ED de les propietats lògiques dels determinants, tenen els mateixos problemes: d'una banda, tenen dificultats per donar compte de l'existència de llengües i/o contextos que permeten violar el principi (i han de recórrer a l'ambigüitat lèxica o construccional) i, de l'altra, no acaben d'oferir una solució al cas dels pronoms. 


\section{$3 \cdot 3$ SOLUCIONS COGNITIVISTES}

Ramos (I998: 43) planteja l'ED com l'efecte secundari d'una gradació que dibuixa una escala cognitiva de definitud, l'esglaó més alt de la qual està ocupat pels pronoms personals:

(I6) I, $2>3>$ tots ('all') $>$ proper noun $>$ common definite animate noun $>$ common definite inanimate noun $>$ common indefinite animate noun $>$ common indefinite inanimate noun $>$ common indefinite animate noun with no determiner $>$ common indefinite inanimate noun with no determiner $>$ abstract noun with no determiner.

A partir d'aquesta escala, les llengües poden fixar diferents «llindars de tolerància», cosa que reflectiria la variació descrita anteriorment i que ni les propostes sintàctiques ni les semàntiques no solucionaven de manera satisfactòria. Per exemple, les llengües com l'anglès, el castellà o el francès marcarien l'acceptabilitat dels pivots en el llindar entre definits i indefinits, mentre que el català o l'italià tindrien un marge de tolerància més gran, situat al voltant dels noms propis.

Aquesta proposta, però, també presenta problemes teòrics i empírics. Des d'un punt de vista merament metodològic, cal destacar que l'escala es construeix a partir de les dades que mira d'explicar; per tant és purament descriptiva llevat que no trobem evidència empírica independent que hi doni suport. Això resulta especialment clar quan hom considera per què els pronoms, que tenen una referència variable assignada pel context com correspon als díctics, haurien de ser considerats més definits que no els noms propis, que, com destaca la bibliografia filosòfica i semàntica, són designadors rígids (Donnellan I972, Fara 2015 o Matushansky 2008). De fet, el català permet lliurement noms propis en posició de pivot, en contrast amb els pronoms, com ja hem vist:

(I7) a. Al vespre, vaig al cafè del «Centro Fraternal». Hi trobo gairebé tots els meus amics. Hi ha Tomàs Gallart, Joan B. Coromina, Enric Frigola, Josep Bofill de Carreres, que tothom coneix per Gori, Lluís Medir, el farmacèutic Casabó, Josep Ganiquer.

b. Fins ara, de conservador sistemàtic, i pesat, només hi havia Enric Jardí.

c. i, de retorn, alguns xicots — entre els quals hi havia notòriament Ferret— fèiem una cosa que avui em sembla demencial i bèstia.

d. L'afirmació és potser hiperbòlica. Hi ha Jaume Roig i els poetes satírics.

A més, des d'un punt de vista empíric, aquesta proposta no sembla tenir un fonament prou sòlid. Per exemple, tot i el diferent llindar que imposen el català i 
Xavier Villalba

Els pronoms forts en les oracions existencials del català

l'anglès, aquesta última llengua permet molts més casos de pivots pronominals que no el català. Mentre el català únicament els admet amb l'adverbi focal només, l'anglès els admet també amb altres adverbis:

(I8) a. and now there was only him, alone on the road,... (Stephen King, The long walk) «I ara només hi havia ell, sol al camí,...»

b. And there was even him tolerating harp music in the midst of it all. * «I hi havia fins i tot ell, que permetia la música d'arpa enmig d'allò»

c. Besides me being a coward there is also HIM stopping me. * «A banda que sóc un covard, hi ha també ell que m’atura.»

Si partim de l'escala que proposa Ramos (1998), no resulta gens obvi com és que una llengua amb un llindar de tolerància menor (l'anglès) admet més excepcions a l'escala que una llengua molt més tolerant (el català).

Per tant, sense descartar el paper que l'escala de definitud pugui tenir en la caracterització de diversos fenòmens sintàctics, no resulta una solució evident per al nostre problema.

\section{$3 \cdot 4$ SOLUCIONS PRAGMÀTIQUES}

Ja hem vist que les solucions sintàctiques i les semàntiques han de superar un escull fonamental: la falta de flexibilitat per donar compte de les nombroses excepcions a l'ED i, sobretot, les prediccions errònies sobre el comportament dels pronoms. També hem vist que la flexibilitat que aporta la solució cognitiva, basada en una escala de definitud, no és empíricament satisfactòria quan s'aplica als pronoms. Per tot això, seguiré la línia traçada per McNally (1992), Abbott (1993), Ward \& Birner (I995) o Zucchi (I995), que mostren de manera convincent que la millor solució ha de ser pragmàtica. No obstant això, tampoc en aquest camp hi ha consens sobre la millor anàlisi. Així doncs, amb diferents matisos, hi ha un bon nombre d'autors que defensen una solució basada en la novetat del referent (McNally I992; Prince I992; Ward \& Birner 1995, 1997):

[a]ll existential there-sentences with definite postverbal NPs can be accounted for by a single pragmàtic principle: that the postverbal NP of a there-sentence represents an entity that is not presumed by the speaker to constitute shared knowledge. That is, the speaker treats the postverbal NP in there-sentences as representing a HEARER-NEW entity (Prince 1992), where a hearer-new entity is one that the speaker does not assume to exist within the hearer's knowledge store. (Ward \& Birner I995, p. 728) 
Aquesta proposta permet explicar els casos de definits en llengües que respecten l'ED, com l'anglès o el castellà: encara que un SD definit és generalment un element familiar, que forma part del discurs i, per tant, incompatible amb la posició de pivot, es pot forçar una lectura pragmàtica que el presenti com si fos nou per al parlant.

Això no obstant, com mostra McNally (1992), la proposta de Prince (1992) i Ward \& Birner (1995) presenta alguns problemes. En primer lloc, la solució no pot donar compte dels casos en què el pivot no denota cap referent, ni vell ni conegut:

(19) a. No hi ha cap taxi disponible.

b. No havia ningú al jardí.

En segon lloc, el criteri tampoc sembla funcionar bé per als casos de pivots pronominals. Com que els pronoms de tercera persona són anafòrics i reben la seva referència d'un antecedent, denoten un referent conegut. Aquest és el cas dels dos contextos següents, que ja hem presentat a la secció 2:

(20) a. Rafael Azcona representa la literatura cinematogràfica. A Itàlia els millors escriptors escrivien per al cinema, però a Espanya, gairebé només hi ha ell. (El Punt, 23/I2/II)

b. Manel Serra, va reconèixer que el debat entre els disset consellers, entre els quals hi ha ell mateix, i el director general, Jordi Blanch,

En tots dos casos, el pronom té un antecedent en el discurs precedent i, per tant, no es pot considerar que el pronom denoti un referent nou per a l'oient, com exigeix l'anàlisi de Ward \& Birner (1995).

Francez (2007), seguint idees d'Abbott (1993, 1997), defensa que l'explicació de l'ED deriva del fet que el pivot de les construccions existencials és rema, és a dir, el constituent informativament més prominent de l'enunciat. A primer cop d'ull, això sembla crear un problema de sobregeneració, perquè en principi qualsevol SN definit, un nom propi o un pronom, poden ser remàtics, la qual cosa prediria que l'ED no hauria d'existir. El punt clau de la seva anàlisi és que normalment hi ha una alternativa a les formes que violen l'ED: la construcció copulativa en què el $\mathrm{SN}$ definit, el nom propi i el pronom apareixen en posició de subjecte, això és, en posició temàtica. Segons Francez, doncs, la possibilitat de tenir (2Ia) bloqueja (2Ib):

(2I) a. John is in the street. «En John és al carrer.»

b. ${ }^{*}$ There is John in the street. «Hi ha en John al carrer.» 
La predicció és que quan no hi ha una alternativa copulativa, un definit podrà aparèixer en la posició de pivot, com en l'exemple següent de Francez (2007: II8):

(22) A: [Qui ens pot venir a buscar a l'aeroport?]

B: There's my father.

expl-is meu pare

«Hi ha el meu pare.»

Encara que enginyosa, la solució de Francez (2007) presenta diversos problemes empírics. En primer lloc, en un context en què demanem qui hi ha al carrer, l'anglès recorre a la forma copulativa amb accent focal sobre John i no pas a la forma existencial:

(23) [Who is on the street?]

"Qui hi ha al carrer?"

a. JoHN is in the street.

"Al carrer hi ha en John.»

b. *There is John in the street.

«Hi ha en John al carrer.»

Aquest comportament és inesperat, perquè la raó de preferir la forma copulativa és poder tenir el SD en posició de tema, però en aquest cas es prefereix aquesta construcció per a un element que és focus. Per què no és possible la construcció existencial?

Això mateix passa en castellà, que funciona, grosso modo, com l'anglès:

(24) a. En la calle està Juan.

"Al carrer hi ha en Juan.»

b. *Hay Juan en la calle.

«Hi ha en Juan, al carrer.»

El castellà tria la forma copulativa amb inversió del subjecte, que rep l'accent focal, en comptes de la forma existencial, en principi més senzilla i adequada.

Sembla clar que mirar d'explicar aquest patró com un cas de bloqueig d'una forma per una altra és poc sòlid.

\section{ANÀLISI}

Fins ara hem vist que cap de les solucions proposades per a l'ED resulta plenament satisfactòria per donar compte del paradigma dels pivots pronominals. En aquesta secció proposo una anàlisi alternativa que parteix d'una premissa diferent: la 
dificultat de tenir pivots pronominals no és un efecte de l'ED, sinó de la conjunció de dos factors. D'una banda, els requisits interpretatius associats a la posició de pivot de les construccions existencials, les quals, com argumenta Leonetti (2008), imposen un intricat conjunt de restriccions informatives i pragmàtiques, que donen lloc al que hem descrit com l'ED. De l'altra, la possibilitat que els pronoms, encara que intrínsecament inadequats per a la posició de pivot, puguin ocupar aquesta posició gràcies a l'obtenció d'una lectura contrastiva per mitjans no convencionals, ja que no poden obtenir la lectura contrastiva per alternança amb la forma pronominal feble. Dos d'aquests mitjans no convencionals són la partícula focal només i el reforç emfatic mateix.

Abans de presentar l'anàlisi, és necessari oferir una breu explicació del funcionament dels pronoms forts en llengües de subjecte nul com el català.

\section{I UNA APROXIMACIÓ NEOGRICEANA ALS PRONOMS FORTS}

Un fet que resulta fonamental quan estudiem els pronoms forts en català és la seva distribució respecte als seus alternants febles o la seva versió nul.la, en el cas del subjecte. Això es pot apreciar en la frase següent:

(25) Vaig veure un home sospitós entre la multitud. (\#Ell) era alt.

Com bé saben els professors de català per a estrangers, els alumnes de llengües com l'alemany, l'anglès o el francès, que exigeixen realitzar sempre el subjecte, acostumen a fer servir pronoms forts en contextos com (25) i triguen a aprendre que l'opció natural i neutra és el subjecte nul.

Això mateix passa en posició de complement, però en aquest cas l'alternança és entre un pronom fort i un pronom feble:

(26) Vaig veure un home sospitós entre la multitud. El vaig observar (\#a ell) amb cura.

Així doncs, per norma el català tria els pronoms nuls i els febles en comptes dels pronoms forts. No obstant això, els pronoms forts sí que són l'opció preferida quan, més enllà de la funció referencial, volem establir un contrast:

(27) No m'ho diguis \#(a mi), digues-l'hi \#(a ell). 
Aquest fet ha portat diversos autors a analitzar els pronoms forts com a inherentment contrastius (Picallo 1994, Rigau 1988b, 1988c, Todolí 2002) i, per tant, a analitzar els contrastos de (25)-(27) com el resultat de la incompatibilitat de trets lèxics dels pronoms amb els diferents contextos.

No obstant això, aquesta anàlisi no pot donar compte d'un contraexemple com el següent:

(28) Vaig veure un home sospitós. Em vaig situar entre ell i la meva família.

En aquest exemple, el pronom fort és l'única alternativa, perquè no hi ha cap pronom nul ni feble que en pugui fer la feina. Sorprenentment, en aquesta circumstància la lectura contrastiva desapareix. Això, evidentment, posa en qüestió la naturalesa intrínsecament contrastiva dels pronoms forts del català i ens deixa amb dues alternatives: assumir l'existència d'una doble sèrie de pronoms forts, uns de contrastius i uns altres de no contrastius, o aplicar la navalla d'Occam i defensar que els pronoms forts són inherentment no contrastius, alhora que derivem la lectura contrastiva com una implicatura conversacional fruit d'un cert ús. Aquí defensaré la segona opció, perquè el patró que acabem de veure encaixa perfectament amb la mena de duplicitats de significats que va analitzar H. Paul Grice (Grice 1975, I98I) en l'estudi de les conjuncions $i$ i $o$ o dels numerals.

Noteu el següent exemple:

(29) La Maria té una amant o una germana secreta.

La interpretació per defecte que fem d'aquesta oració és exclusiva: o la Maria té una amant o la Maria té una germana secreta, però no totes dues. Ara bé, com va mostrar Grice, la frase és igualment certa en la lectura inclusiva: la Maria té una amant o la Maria té una germana secreta o totes dues. Grice considera que aquesta duplicitat de significat de la conjunció disjuntiva no està codificada en el lèxic, perquè això suposaria una duplicitat poc desitjable, sinó que $o$ només té el significat inclusiu ( $A$ o $B$ o $A$ i B). Aleshores, el significat més fort ( $\mathrm{o}$ o $B$, però no $A$ i $B$ ) es genera com una implicatura conversacional i és, per tant, un significat pragmàtic i no pas semàntic. ${ }^{5}$ Lestratègia conversacional és ben simple: si el parlant hagués volgut destacar el sentit inclusiu, hauria recorregut a una solució més clara i senzilla: la conjunció $i$ («La

5. Aquesta solució és una conseqüència de la modificació que fa Grice del Principi de la Navalla d'Occam: «Senses are not to be multiplied beyond necessity» (Grice 1989: 47). 
Maria té una amant i una germana secreta»). Com que el parlant no ha triat aquesta opció més informativa, el parlant infereix que el parlant no volia transmetre aquesta interpretació i es genera la implicatura conversacional «però no totes dues». D'aquesta manera, Grice ens ofereix un mecanisme molt eficient per generar significats de manera regular gràcies a estratègies comunicatives i simplificar, doncs, la semàntica.

Seguint les idees originals de Levinson (I987) que va ampliar Huang (I99I, 1994) (vegeu també els treballs de Mayol 20Io i Mayol \& Clark 20 Io en el marc de la teoria de jocs), podem estendre l'anàlisi de Grice a l'alternança entre pronoms forts d'una banda i pronoms nuls i febles de l'altra. La idea fonamental és que la tria lèxica no és una opció aïllada, sinó que suposa triar entre alternatives, la qual cosa pot generar implicatures conversacionals quan interactua amb les màximes griceanes que regeixen la conversa. Agafem, per comoditat, els dos principis bàsics de Levinson $(1987,2000){ }^{6}$

(30) El principi d'Informativitat (principi-I)

«Digues el mínim necessari», és a dir, produeix la informació lingüística mínima necessària per assolir els teus objectius comunicatius.

(31) El principi de Manera (principi-M)

«No facis servir una expressió prolixa, obscura o marcada sense motiu.»

És facil de veure que en català la combinació d'aquests dos principis conversacionals afavoreix per defecte els pronoms nuls i febles per damunt dels forts, que sempre seran l'opció marcada. ${ }^{7}$ Efectivament, en català l'ús purament referencial dels pronoms rebutja els pronoms forts si hi ha l'alternativa més simple, com hem vist als exemples de (25)-(26), que repeteixo per comoditat:

(32) Vaig veure un home sospitós entre la multitud. (\#Ell) era alt.

(33) Vaig veure un home sospitós entre la multitud. El vaig observar (\#a ell) amb cura.

En canvi, noteu que quan fem servir el pronom fort, en competència directa amb l'alternativa més simple, la lectura és necessàriament contrastiva:

(34) No m'ho diguis \#(a mi), digues-li-ho \#(a ell).

6. El principi-I de Levinson està basat en les màximes de quantitat de Grice: «Make your contribution as informative as is required (for the corrent purposes of the Exchange)» $\mathrm{i}$ «Do not make your contribution more informative than is required" (Grice 1989: 26).

7. Com assenyala un revisor anònim, aquesta idea també rep una formulació sintàctica en la gramàtica generativa: l'Avoid Pronoun Principle (Principi d'Evitació del Pronom) de Chomsky (198I). Vegeu Picallo (I994) per a una aplicació al català.

Caplletra 65 (Tardor, 2018), pp. 69-94 
L'explicació se segueix de manera senzilla del principi-M: ${ }^{8}$ el parlant fa servir una opció marcada (el pronom fort) en comptes d'una de no marcada (el pronom feble i prou), cosa que viola el principi-M, però si assumeixo que vol ser cooperatiu, infereixo que ho fa per una raó comunicativa, per exemple, aportar un valor contrastiu. Per tant, en aquests contextos en què els pronoms febles i els forts poden alternar, el pronom fort rep necessàriament valor contrastiu.

Fins ara, l'anàlisi lexicalista i la pragmàtica fan prediccions semblants. El que marca la diferència és la predicció que es fa per al cas en què el pronom fort és l'única alternativa, com a l'exemple (35), que repeteixo per comoditat:

(35) Vaig veure un home sospitós. Em vaig situar entre ell i la meva família.

Ja hem vist que si assumim que els pronoms forts són intrínsecament contrastius, la predicció és que també aquí hauríem de tenir una lectura contrastiva, però aquesta predicció és incorrecta. En canvi, el model neogriceà que hem defensat aquí sí que fa la predicció correcta: com que la lectura contrastiva és fruit d'una implicatura conversacional generada per la tria entre dues alternatives respecte al principi-M, si no hi ha alternativa, perquè la coordinació exigeix un pronom fort, tampoc no tindrem lectura contrastiva. ${ }^{9}$

Per tant, podem concloure que la naturalesa contrastiva dels pronoms forts del català (i per extensió de les altres llengües de subjecte nul romàniques) no està codificada lèxicament, sinó que és una implicatura conversacional generada per la tria entre alternatives més o menys marcades i l'efecte dels principis conversacionals, concretament el Principi-I i el Principi-M.

\subsection{ELS PIVOTS PRONOMINALS I EL CONTRAST}

Ja hem notat a la secció 2 que els gramàtics catalans han descrit la impossibilitat de pivots pronominals, però també hem vist a la secció 3 que l'ED no explica aquesta

8. Evidentment, com correspon a una anàlisi (neo)griceana, en el rerefons sempre hi ha el Principi de Cooperació, que assumeix que els parlants d'una conversa miren de ser cooperatius i ajudar a fer progressar la comunicació: «Make your conversational contribution such as is required at the stage a tit occurs, by the accepted purpose or direction of the talk Exchange in which you are engaged» (Grice 1989: 26).

9. Com assenyala un revisor anònim, atès que és la sintaxi qui fa possible o no les alternatives, l'anàlisi és en últim terme gramatical o, almenys, gramatical i pragmàtica. Aquesta caracterització, però, no afecta la validesa de l'anàlisi proposada. 
restricció. Ara que tenim una anàlisi dels pronoms forts del català, podem mirar de lligar-la amb les oracions existencials. Mirem, doncs, com encaixa la posició de pivot en el sistema descrit a 4.I.

El punt fonamental és un fet força conegut; la construcció existencial no admet els pronoms febles definits, com es pot apreciar a l'exemple següent: ${ }^{10}$

(36) A: En aquella festa també hi havia la teva germana?

B: *No, no la hi havia. (Ramos 1998$)^{11}$

Per tant, en la posició de pivot no podem trobar l'alternança entre els pronoms febles i els forts que generava la implicatura conversacional de contrast, la qual cosa ens permet predir que els pronoms forts que hi puguin aparèixer no seran contrastius, sinó simplement anafòrics. Justament, això ens dóna una explicació de la dificultat de tenir pivots pronominals: d'una banda, el pronom només podrà ser anafòric i, de l'altra, com argumenta Leonetti (2008), els pivots no poden ser anafòrics. Ens trobem, doncs, en una situació que ens prediu que els pronoms seran impossibles en posició de pivot, la qual cosa, com hem vist, és certa fins a cert punt.

No obstant això, podem sortir de l'atzucac si afegim de manera externa algun element que doti els pronoms de la força contrastiva necessària per poder ocupar la posició de pivot. I justament aquests mecanismes són els que hem vist a la secció 2: la partícula focal només, la partícula emfatica mateix i (possiblement) la coordinació. Considereu, per exemple, el paper de només en els exemples següents: ${ }^{12}$

IO. De fet, el català tendeix a tractar els pivots com el subjecte dels verbs inacusatius, com ens mostra la preferència per la concordança en la majoria de dialectes (Rigau 1994b, 1997, 2005) i la pronominalització pel clític partitiu:

(i) N'hi havien dos.

II. El castellà (o el gallec) admeten la pronominalització del pivot mitjançant un pronom feble definit:

(i) Estudiantes, los hay bastante buenos.

«D'estudiants, n’hi ha de força bons.»

No obstant això, com mostren Longa et al. (1998), el pivot és indiscutiblement indefinit, com ens demostra la traducció catalana, que recorre al clític partitiu en/ne. Així doncs, segons aquests autors, l'ús del clític definit seria un «mecanisme de reciclatge» de pronoms per suplir la manca de clític partitiu.

I2. Beaver et al. (2006) van quantificar l'efecte de la partícula focal only 'només' en les existencials de l'anglès: «What we find is that the presence of only makes the NP substantially more existential, by a factor of approximately IO,००0», p. 32. 
Xavier Villalba

Els pronoms forts en les oracions existencials del català

(37) a. I només hi havia ella que el pogués aturar. (Sebastià Juan Arbó, Hores en blanc, p. 64)

b. d'empleats només hi havia ella i una auxiliar. («Rodalies de Catalunya: molta feina per fer» - El Punt Avui, Io/ı1/2010)

Per veure l'aportació de només, cal aprofundir un xic en la seva semàntica. Com és habitual amb les partícules focals, només consta d'una part assertiva (per exemple, a (37a) «no hi havia ningú més fora de mi que la pogués aturar») i una part implicada o pressuposada (per exemple, a (37a) «jo la podia aturar») (Rooth 1985: 120). No obstant això, com destaquen Beaver \& Clark (2008: 252), l'anàlisi no fa justícia a la contribució d'aquesta partícula: «The presence of an expectation that something stronger than the prejacent [= la part implicada o pressuposada] is true is an essential part of the meaning of only.» Ho exemplifiquen amb el contrast següent, que adapto del seu exemple anglès:

(38) a. M'esperava una suite, però només vaig aconseguir una habitació individual amb dos llits.

b. \#M'esperava una habitació individual amb dos llits, però només vaig aconseguir una suite.

Com que només va associat a una expectativa més forta, (38a) és coherent: la part pressuposada «una habitació individual amb dos llits» és més feble que l'expectativa («obtindré una suite»). En canvi, a (38b), la part pressuposada és més forta que no l'expectativa, cosa que resulta incompatible amb el sentit d'expectativa de només.

Si traslladem aquesta observació al nostre àmbit, podem veure que la presència de només fa que els pivots pronominals estableixin un contrast entre el referent del pronom i un conjunt d'expectatives més gran, associat a només. Així doncs, encara que el pronom no pot obtenir el valor contrastiu per ell mateix, com prediu la nostra anàlisi neogriceana de la distribució dels pronoms, gràcies a la presència de només obtenim una alternativa que permet al pronom adquirir valor contrastiu i, per tant, esdevenir apropiat per a la posició de pivot.

El segon gran grup de pivots pronominals es forma amb la partícula emfatica mateix:

(39) a. al president li han començat a créixer enemics — entre els quals hi ha ell mateix-. (Josep M. Espinàs, «Una història poc exemplar» - El Periódico, 9/07/2008)

b. uns quants, entre els quals hi havia jo mateix, [...] («No volem tombes»-Revista de Cambrils, 07/1997) 
c. els disset consellers, entre els quals hi ha ell mateix (Associació de promotors de Barcelona, "Caixa Girona condiciona la fusió a un consell territorial»)

El rol pragmàtic d'aquest element és destacar o singularitzar el referent del pronom respecte dels altres membres del conjunt que el conté, la qual cosa crea la lectura contrastiva necessària perquè el pronom pugui aparèixer en la posició de pivot. Aquesta idea rep suport de l'existència d'exemples com els següents, en què el sentit de contrast es vehicula a través de construccions específiques:

(40) a. D’una banda hi havia ella i de l'altra la resta del món,...

b. Em semblà que a la meva esquerra no hi havia ella sinó Alberta.

c. «...per la manera com actuava amb mi vaig sentir que era l'única. Després vaig saber que hi havia ella i em vaig sentir enganyada», afirma l'actriu.

En aquest cas és evident el paper clarament contrastiu del pivot pronominal respecte a un altre individu o conjunt d'individus.

Un cas similar és el següent, en què se singularitza un referent pronominal respecte a un conjunt:

(4I) a. pels funcionaris en vaga, entre els quals hi havia jo i alguns dels que sou aquí. (Pasqual Maragall, «Solemne signatura de l’acord per a un govern catalanista d'esquerres a la Generalitat de Catalunya». http://www.unitatdaran.org/2003/r2/solemne-signaturade-lacord-per-a-un-govern-catalanista-i-desquerres-a-la-generalitat-de-catalunya/)

b. unes quantes dones, entre les quals hi havia ella i Victòria. (Carme Rodríguez Virgili, Benvinguda, Marta, p. 180)

Finalment, com em fa notar un revisor anònim, aquesta anàlisi pot donar compte de la lectura de llista que hem esmentat quan parlàvem dels exemples de (5)(7), en què l'anglès viola l'ED. Efectivament, la noció de llista sembla anar lligada a la generació d'alternatives en contrast, que és precisament la condició que permet la presència de pronoms forts en les existencials.

En resum, he mostrat que segons l'anàlisi neogriceana dels pronoms, els pronoms forts no poden rebre una lectura contrastiva en la posició de pivot, perquè la falta d'alternança amb una variant nul.la o feble impedeix que es generi la implicatura de contrast. No obstant això, els pivots pronominals poden rebre aquesta lectura contrastiva per mecanismes marcats, com ara la partícula focal només i la partícula emfatica mateix. En tots dos casos, es generen alternatives amb les quals el pivot pronominal pot contrastar, cosa que l'habilita com a pivot. Si aquesta anàlisi, que 
Xavier Villalba

Els pronoms forts en les oracions existencials del català

deslliga la legitimació dels pivots pronominals de l'ED, és correcta, podem esperar de trobar un comportament similar no només en llengües com el català, que no respecten l'ED, sinó també en llengües que sí que ho fan. En la pròxima secció, mostraré que la predicció és correcta.

\subsection{MÉS ENLLÀ DEL CATALÀ}

A 4.2 hem vist que el contrast i l'èmfasi contribueixen de manera decisiva a permetre la legitimació de pivots pronominals en les construccions existencials del català. En aquesta secció mostraré que això no és fet exclusiu del català, sinó que altres llengües, especialment les que respecten l'ED, també admeten els pivots pronominals en les mateixes condicions, amb petits matisos.

Si considerem l'italià, que es comporta com el català respecte a l'ED, el patró és molt clar, amb la presència de les partícules solo 'només' i stesso 'mateix':

(42) a. Roberto Baggio: «Per me c'è solo lei». "Roberto Baggio: "Per mi, només hi ha ell"."

b. in Italia c'è solo Balotelli perchè di talenti in avanti c'è solo lui... «a Itàlia només hi ha Balotelli, perquè amb talent a la davantera només hi ha ell...»

(43) a. Perche' al potere ci sono loro stessi. "Perquè al poder hi són ells mateixos.»

b. dato che al governo ci sono loro stessi. "com que al govern hi són ells mateixos»

c. se si crede che dietro il Croce c'è lui stesso (Innocenzo Cervelli, 1977, Gioacchino Volpe)

«si es creu que dintre del Croce hi ha ell mateix»

No obstant això, la prova crucial prové de les llengües que respecten l'ED. Si, com he argumentat, la legitimació dels pivots pronominals no és una conseqüència de l'ED, sinó de la disponibilitat d'una lectura contrastiva, podem esperar que en una llengua que respecti l'ED per als SD, admeti, tanmateix, pivots pronominals en les condicions adequades. Aquesta predicció es compleix fil per randa en llengües com l'anglès:

(44) a. there are no other gods, because there was only he at first [...] (Howard Fast, Moses: The Epic Story of His Rebellion in the Court of Egypt)

"no hi ha altres dues, perquè només hi havia ell al començament» 
b. and now there was only him, alone on the road, [...] (Stephen King, The long walk) «i ara només hi havia ell, sol a la carretera,»

c. He was on her mind continually, invading her thoughts, pushing out everything insane until there was only him. (Christine Feehan, Dark prince)

«Sempre el tenia al cap, li envaïa els pensaments, fent fora tota la bogeria fins que només hi havia ell.»

De fet, tenim el mateix patró en castellà, que és molt restrictiu en la possibilitat de pivots pronominals:

(45) a. Agapita, que solo había ella con ese nombre, [...] (La casa (II): La familia tradicional sanabresa. https://lenguajesculturales.wordpress.com/2010/o8/23/guia-cultural-desanabria-la-casa-ii-la-familia-tradicional-sanabresa/>)

b. entonces solo habíamos nosotros. (La verdad del amor, cap. I2. <http://www.fotolog. com/laverdaddelamor/92508648/>)

c. Solo habían ellos dos. (Hoja de Lagomar, juliol de 2006. <http://gambarde.blogspot. com/2006_07_or_archive.html>)

d. De niño veía Yola obligado, porque sólo había ella y Mirtha Patiño como opciones televisivas para los niños.

e. A finales del vídeo, Alanis sale del coche, y en el coche sólo había ella.

Generalment, aquestes frases es construirien amb el verb estar, que és la forma que substitueix de manera natural les construccions existencials amb formes definides, com es pot veure en el contrast entre el català i el castellà:

(46) a. A la taula hi ha el llibre.

b. En la mesa està el libro.

Finalment, com apunta un revisor anònim, les dades de l'anglès de (I8), que reprodueixo per comoditat a (47), suggereixen que hi ha diferents mecanismes i altres partícules focalitzadores que poden aconseguir aquest efecte, amb diferències entre llengües que cal estudiar.

(47) a. and now there was only him, alone on the road,... (Stephen King, The long walk) «I ara només hi havia ell, sol al camí,...»

b. And there was even him tolerating harp music in the midst of it all.

* «I hi havia fins i tot ell, que permetia la música d'arpa enmig d'allò»

c. Besides me being a coward there is also HIM stopping me.

* «A banda que sóc un covard, hi ha també ell que m’atura.» 
Evidentment, cal una anàlisi de corpus detallada abans d'extraure conclusions fermes sobre el funcionament dels pivots pronominals des d'una perspectiva interlingüística, però les dades mostrades ofereixen una base sòlida per mantenir l'anàlisi aquí defensada, és a dir, que el comportament dels pivots pronominals no es pot reduir a un subtipus de l'ED, sinó que és el resultat de l'especial combinació de les condicions informatives que imposa la construcció existencial amb la naturalesa pragmàtica del contrast en les formes pronominals.

\section{CONCLUSIONS}

En aquest article es defensa que l'Efecte de Definitud (ED), que trobem a les oracions existencials de moltes llengües del món, no ens ajuda a explicar el comportament dels pivots pronominals. En primer lloc, he mostrat que la prohibició de tenir pronoms forts en la posició de pivot no és absoluta, ni tan sols en llengües que respecten l'ED. En segon lloc, he mostrat que les diverses formulacions de l'ED no poden donar compte d'aquest comportament. En tercer lloc, he proposat que el comportament dels pivots pronominals s'explica per la conjunció de les condicions informatives que imposa la construcció existencial, que requereix que el pivot sigui contrastiu, amb la naturalesa pragmàtica del contrast en les formes pronominals, que impedeix la lectura contrastiva justament en la posició de pivot perquè no hi ha possibilitat d'alternança amb un pronom nul o feble. En quart lloc, he proposat que els casos de pivot pronominal necessiten obtenir aquesta lectura contrastiva per mitjans alternatius, especialment mitjançant l'aportació de les partícules només i mateix. Finalment, he mostrat que aquesta anàlisi es pot estendre a llengües que respecten l'ED, com ara l'anglès o el castellà.

XaVier Villalba

Universitat Autònoma de Barcelona xavier.villalba@uab.cat

ORCID oooo-0ooI-6993-976X 


\section{REFERÈNCIES BIBLIOGRÀFIQUES}

Аввотт, В. (1993) «A pragmatic account of the definiteness effect in existencial sentences", Journal of Pragmatics, 19, pp. 39-55. DOI: 10.1016/0378-2166(93)90069-2.

- (I997) «Definiteness and existentials», Language, 73, pp. I03-I08. DOI: I0.2307/416595.

BARWISE, K. J. \& R. COOper (198I) «Generalized quantifiers and natural language», Linguistics and Philosophy, 4, pp 159-219. DOI: 10.1007/BFoo350139.

Beaver, D. \& B. Clark (2008) Sense and sensitivity. How focus determines meaning, Londres, Blackwell Publishers.

Beaver, D., I. Francez \& D. Levinson (2006) «Bad subject: (Non-)canonicality and NP distribution in existentials», dins E. Georgala \& J. Howell (eds.), Proceedings of Semantic and Linguistic Theory XV, Ithaca, NY, Cornell University Press, pp. 19-43.

Belletti, A. (1987) «Los inacusativos como asignadores de caso», dins V. Demonte \& M. Fernández-Lagunilla (eds.), Sintaxis de las lenguas románicas, Madrid, El Arquero, pp. 167-230.

- (1988) «The case of unaccusatives», Linguistic Inquiry, I9, pp. I-35.

Bentley, D. (20I4) «Subject canonicality and definiteness effects in Romance theresentences», Language, 89, pp. 675-712. DOI: 10.1353/lan.2013.0062.

Bentley, D., F. M. Ciconte \& S. Cruschina (20I5) Existentials and locatives in Romance dialects of Italy, Oxford, Oxford University Press.

Brucart, J. M. \& G. Rigau (2002) «La quantificació», dins J. Solà, M. R. Lloret, J. Mascaró i M. Pérez-Saldanya (eds.), Gramàtica del català contemporani contemporani, II, Barcelona, Empúries, pp. I517-I589.

Сномsку, N. (198I) Lectures on government and binding, Dordrecht, Foris.

Cruschina, S. (2015) "Patterns of variation in existential constructions», Isogloss. A journal on variation of Romance and Iberian languages, I, pp. 33-65. [En línia: http://revistes.uab.cat/isogloss/article/view/vi-nI-cruschina.]

Donnellan, K. S. (1972) «Proper names and identifying descriptions», dins D. Davidson \& G. Harman (eds.), Semantics of natural language, Dordrecht, Reidel, pp. 356-379.

Fara, D. G. (2015) «Names are predicates», Philosophical Review, I24, pp. 59-II7. DOI: IO.I215/00318108-2812660.

Fischer, S., T. Kupisch \& E. Rinke, eds. (20I6) «Definiteness effects. Bilingual, Typological and Diachronic Variation», Cambridge, Cambridge Scholars Publishing.

FranCeZ, I. (2007) Existential propositions, tesi doctoral, Stanford University. 
Xavier Villalba

Els pronoms forts en les oracions existencials del català

GrIce, H. P. (1975) «Logic and conversation», dins P. Cole \& J. Morgan (eds.), Syntax and Semantics, III, Nova York, Academic Press, pp. 4I-58. DOI: I0.IIII/j.I3652664.2006.0I229.x. [Reeditat en Grice (1989).]

- (198I) «Presupposition and conversational implicature», dins P. Cole (ed.), Radical Pragmatics, Nova York, Academic Press, pp. I83-198. [Reeditat en Grice (1989)].

- (1989) Studies in the way of words, Cambridge, Mass., Harvard University Press.

HuANG, Y. (I99I) «A neo-Gricean pragmatic theory of anaphora». Journal of Linguistics, 27, pp. 30I-335. DOI: I0.1017/So022226700012706.

- (1994) The syntax and pragmatics of anaphora, Cambridge, Cambridge University Press. DOI: I0.10I7/CBO9780511554292.006.

Keenan, E. L. (2003) «The definiteness effect: Semantics or pragmatics?», Natural Language Semantics, II, pp. 187-216.

Leonetti, M. (2008) «Definiteness effects and the role of the coda in existential constructions», dins A. Klinge \& H. H. Muller (eds.) Essays on Nominal Determination: From morphology to discourse management, Amsterdam, John Benjamins, pp. I3I-I62.

- (20I6). «Definiteness effects: the interplay of Information Structure and pragmatics», dins S. Fischer, T. Kupisch \& E. Rinke (eds.), «Definiteness effects. Bilingual, Typological and Diachronic Variation», Cambridge: Cambridge Scholars Publishing, pp. 66-II9.

Levinson, S. C. (1987) «Pragmatics and the grammar of anaphora», Journal of Linguistics, 23, pp. 379-434. DOI: 10.1017/So022226700011324.

Longa, V. M., G. Lorenzo \& G. Rigau (I998) «Subject clitics and clitic recycling: Locative sentences in some Iberian Romance languages», Journal of Linguistics, 34, pp. I25-164.

Lumsden, M. (1988) Existential structures, Londres, Croom Helm.

Matushansky, O. (2008) «On the linguistic complexity of proper names», Linguistics and Philosophy, 31, pp. 573-627. DOI: 10.1007/sio988-008-9050-I.

MaYol, L. (2010) "Contrastive pronouns in null-subject Romance languages», Lingua, I20, pp. 2497-25I4. DOI: I0.I0I6/j.lingua.20I0.04.009.

Mayol, L. \& R. Clark (2OIO) «Pronouns in Catalan: Games of partial information and the use of linguistic resources", Journal of Pragmatics, 42, pp. 78I-799. DOI: I0.IOI6/j.pragma.2009.07.004.

McNalLy, L. (1992) An interpretation for the English existential construction, tesi doctoral, University of California, Santa Cruz.

MiLsARK, G. (1974) Existential sentences in English, tesi doctoral, MIT. 
- (1977) «Toward an explanation of certain peculiarities of the existential construction in English», Linguistic Analysis, 3, pp. I-29.

Picallo, C. (1994) "Catalan possessive pronouns: The Avoid Pronoun Principle revisited", Natural Language \& Linguistic Theory, I2, pp. 259-299. DOI: I0.I007/ BFoo993I46.

Prince, E. F. (1992) «The ZPG letter: Subjects, definiteness, and information-status», dins S. Thompson \& W. Mann (eds.), Discourse Description: Diverse Analyses of a Fundraising Text, Filadèlfia/Amsterdam, John Benjamins, pp. 295-325.

Ramos, J.-R. (1998) «Presentational sentences in Catalan dialects», Catalan Working Papers in Linguistics, 6, pp. 4I-58.

- (200I) «El verb haver-hi: evolució dels usos sintàctics», Estudis Romànics, xxiII, pp. I23-I46.

- (2002) «El SV, II: la predicació no verbal obligatòria», dins J. Solà, M. R. Lloret, J. Mascaró \& M. Pérez Saldanya (eds.), Gramàtica del català contemporani, II, Barcelona, Empúries, pp. 195I-2044.

Rando, E., \& D. J. Napoli (1978) "Definites in there-sentences», Language, 54, pp. 300-313. DOI: $10.2307 / 412949$.

Rigau, G. (1988a) «Els predicats no verbals i l'efecte d'especificitat», Estudi General, 8, pp. 5I-64.

- (1988b) «Strong pronouns», Linguistic Inquiry, 19, pp. 503-5II.

- (1988c) Gramàtica del discurs, Bellaterra (Cerdanyola del Vallès), Servei de Publicacions de la UAB.

- (1994a) «El comportamiento sintáctico de los predicados existenciales en catalán», Revista de Lengua y Literatura Catalana, Gallega y Vasca, 3, pp. 33-53.

- (1994b) «Catalan presentational sentences and the properties of Agr nodes», dins G. Cinque, J. Koster, J.-Y. Pollock, L. Rizzi \& R. Zanuttini (eds.), Paths towards Universal Grammar, Washington, Georgetown University Press, pp. 343-359.

- (1997) «Locative sentences and related constructions in Catalan: esser/haver alternation", dins A. Mendikoetxea \& M. Uribe-Etxebarría (eds.), Theoretical Issues at the morphology-syntax interface, Bilbao, Universidad del País Vasco, pp. 395-42I. - (2005) «Number agreement variation in Catalan dialects», dins G. Cinque \& R. Kayne (eds.), The oxford handbook of comparative syntax, Oxford, Oxford University Press, pp. 775-805.

Rоотн, M. (1985) Association with focus, tesi doctoral, University of Massachusetts, Amherst.

SAfIR, K. (1985) Syntactic chains, Cambridge, Cambridge University Press. 
Xavier Villalba

Els pronoms forts en les oracions existencials del català

Todolí, J. (2002) «Els pronoms», dins J. Solà, M. R. Lloret, J. Mascaró \& M. Pérez Saldanya (eds.), Gramàtica del català contemporani, II, Barcelona, Empúries, pp. I337-I433.

WARD, G. \& B. J. Birner (I995) «Definiteness and the English existential», Language, 7I, pp. 722-742. DOI: I0.2307/415742.

— (1997) «Response to Abbott», Language, 73, pp. I09-II2. DOI: I0.2307/416596.

ZucCHI, A. (1995) «The ingredients of definiteness and the definiteness effect», Natural Language Semantics, 3, pp. 33-78. DOI: I0.1007/BFoI252884. 